\title{
Design Patterns of Investing Apps and Their Effects on Investing Behaviors
}

\author{
Sayan Chaudhry \\ sayanc@andrew.cmu.edu \\ Carnegie Mellon University \\ Pittsburgh, Pennsylvania, USA
}

\author{
Chinmay Kulkarni \\ chinmayk@cs.cmu.edu \\ Carnegie Mellon University \\ Pittsburgh, Pennsylvania, USA
}

\begin{abstract}
Smartphone apps such as Robinhood and Public that promise to "democratize investing" have risen in popularity over the past few years. These apps allow retail investors, who often possess little prior investing experience, to trade stocks, options, and other securities easily and inexpensively, often commission-free. It seems plausible that the interaction patterns of these new apps may significantly influence trading behaviors of their users. But so far, there is little formal design guidance on how such apps should be designed. This paper introduces a set of design guidelines for encouraging healthy investing behaviors by drawing on three bodies of related work: 1) findings from finance and economics literature on healthy investment practices, 2) the dual process theory from behavioral sciences, and 3) design metaphors used in interfaces with uncertain rewards. Using these guidelines, we qualitatively analyze the user interfaces of some popular investment platforms. Our analysis reveal that, unfortunately, popular trading apps generally do not follow design patterns that encourage healthier trading behaviors. We discuss design implications and opportunities for future design.
\end{abstract}

\section{CCS CONCEPTS}

- Human-centered computing $\rightarrow$ Human computer interaction (HCI); Interaction design.

\section{KEYWORDS}

investment; financial wellness; behavioral finance; design guidelines; cryptocurrency

\section{ACM Reference Format:}

Sayan Chaudhry and Chinmay Kulkarni. 2021. Design Patterns of Investing Apps and Their Effects on Investing Behaviors. In . ACM, New York, NY, USA, 12 pages. https://doi.org/10.1145/3461778.3462008

\section{INTRODUCTION}

In recent years, smartphone-based trading applications that promise to "democratize investing" have shifted the stock market from being territory exclusive to institutional and wealthy investors and opened it up to less privileged individuals [59]. This expansion of access is exemplifed by apps such as Robinhood, Webull, and Public

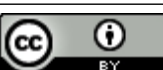

This work is licensed under a Creative Commons Attribution International 4.0 License.

DIS '21, June 28-fuly 2, 2021, Virtual Event, USA

(c) 2021 Copyright held by the owner/author(s).

ACM ISBN 978-1-4503-8476-6/21/06.

https://doi.org/10.1145/3461778.3462008 that have become popular in recent years $[87,88]$. Unlike traditional brokerage firms, these apps require no minimum amount to be invested. Furthermore, while traditional brokerages charged investors every time they bought or sold an investment, newer apps do not charge commissions for most kinds of securities. Together, this makes these apps more attractive to less wealthy investors, who seek to avoid the expenses of investing. So attractive are these offerings that even traditional brokerages are eliminating fees and investment minimums in order to remain competitive [22,98]. Overall, these trends potentially open up investing to less wealthy people, specifically to "retail" investors, defined as those who invest their own money and have no professional training in investing.

We argue that this transition from a traditional, high cost, and high barrier to entry interaction with financial market to a disruptive, zero-commission, and nearly effortless experience [9] for retail investing constitutes a fundamental shift in investing, one of the most consequential human behaviors. It is thus worthy of close study by the design community.

Not only has easy and free access to trading lured millions of people, especially first-time retail investors, to these platforms [72, 93], these apps also afford novice investors one-click access to invest in riskier securities such as cryptocurrencies and options [86]. Some evidence suggests that during the COVID-19 pandemic, people confined to their home repurposed the money they could no longer spend on recreation to speculation on these apps which were just a download away [55]. As recent episodes with companies like GameStop demonstrate, these apps have also allowed inexperienced investors to adopt riskier strategies such as "short squeezing" [76]. Some estimates suggest that more than a quarter of Americans bought "meme" stocks in 2021 and a majority faced a loss [91]. For some, devastating losses have had catastrophic results [8, 72, 75]. In short, the rise of zero-commission trading apps has both vastly expanded the reach of investing and qualitatively changed its nature.

Given this background, it is easy to how design might contribute in shaping investing behavior. Through its design, a trading platform can determine which actions and behaviors are easily available to users, and thus encouraged [63]. It could also discourage certain actions. To make an analogy, consider social networking apps. Snapchat, with its focus on ephemeral content and gesture-heavy user interface, has a very different appeal compared to other platforms like Facebook and Reddit. It encourages different kinds of content to be posted, even in a narrowly defined topic such as national elections [13]. Similarly, one could expect design decisions made by investing apps to affect investing behavior.

More specifically, investing apps can be considered as technical and social choice architectures that influence investing behavior. Extending research on digital choice architectures [39], one can expect that the design, structure, and features of investing apps 

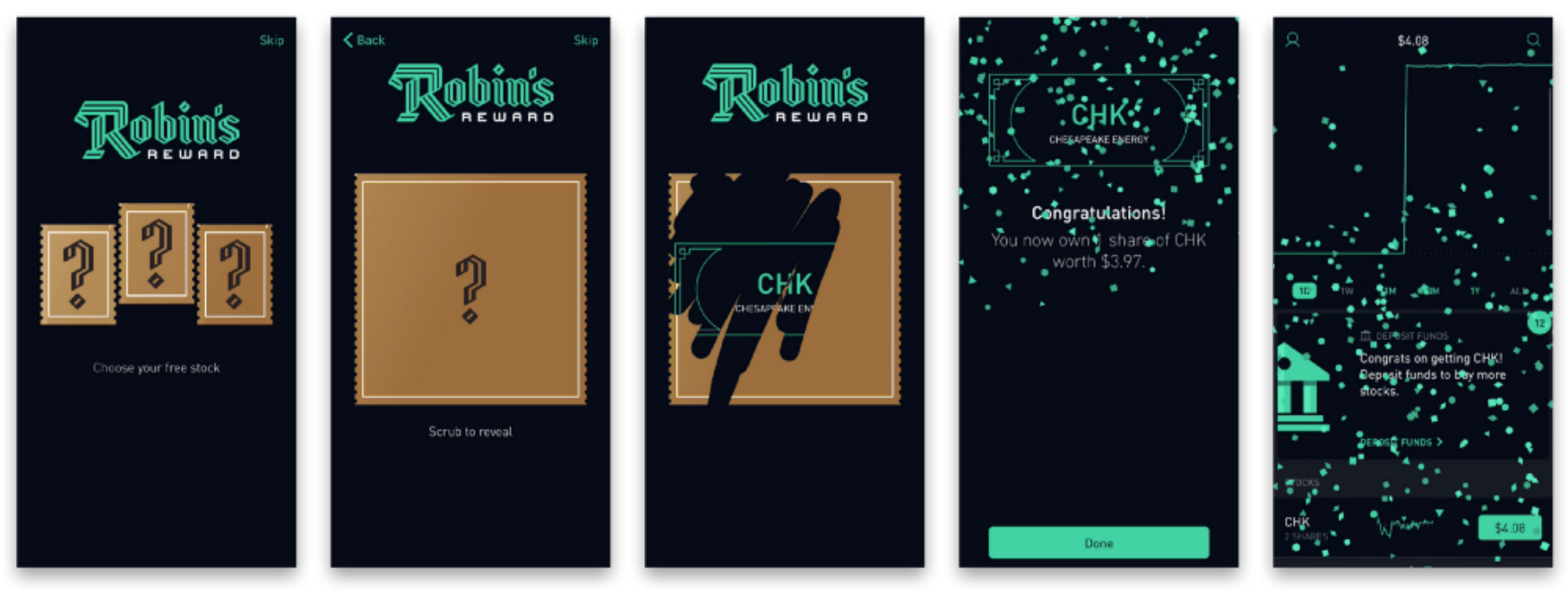

Figure 1: Robinhood offers its users a free stock when joining the platform or referring a friend. This flow uses a lottery scratchcard interface. Such design patterns may lead users to conflate the idea of investing with gambling. Image from Tory Hobson/Pinch Pull Press (https://link.medium.com/uxXrSIPuCdb).

can also enable and constrain specific behaviors in users. Certain design decisions can encourage investors to act on their instincts and possibly be less rational, while other alternative decisions might encourage systematic deliberation $[12,77]$. For instance, absence of commissions for each trade in most popular investing apps can encourage more people to trade more frequently. Similarly, the use of "golden tickets", and confetti, and free stocks, as seen in Robinhood's interface (Figure 1) may blur the lines between an investing app and one for lotteries and gambling [34, 93]. In sum, the design of smartphone trading platforms may prevent or encourage investors in making fully informed decisions [59].

Despite the large impact that design patterns can have on investing behaviors, research on this topic is unfortunately lacking. We note that there is a long history of research in the design community on how individuals, especially from vulnerable populations make budgeting decisions [43] and how design can induce healthier budgeting habits $[10,23]$.

However, this prior literature does not always apply to investing, because of three critical differences between budgeting and saving activities, and investing in stocks and other risky instruments. First, saving and budgeting behaviors are strongly embedded in culture. For instance, immigrants to the United States in the early 20th century repurposed empty soup cans to earmark savings for different goals [95]. This practice is not altogether different from contemporary practices of spending and saving through different credits cards and bank accounts [43]. These cultural norms both offer a guide for what is reasonable behavior and discourage behavior that is economically sound but socially irresponsible, such as raiding children's piggy banks to pay for an unexpected expense [95]. Unfortunately, barring discouraging speculation, there are few cultural practices around successful investing [20]. Second, successful saving and budgeting behaviors are often straightforward and intuitive to adults, but successful investing requires counterintuitive thinking. For instance, it is intuitive to most adults that it is better to save more in times of economic stability for a rainy day. It is less clear whether it is similarly better to purchase more stocks in times of economic stability when stock prices may be inflated [11]. Third, and perhaps most important, investing is inherently risky. While saving money in a bank account guarantees a riskfree return, investors also stand the chance to lose their capital and suffer ruinous losses. As such, the heuristics investors use to evaluate the trade-off between risks and potential rewards can play a big role in their success [8]. These critical differences between saving and investing suggest that design implications from studies on budgeting behaviors are unlikely to be sufficient to inform the design of investing interfaces.

This paper starts to fill this gap of design guidance. In doing so, we take inspiration from methods for creating design guidance in other fields without thick cultural practices, a need for counterintuitive thinking, and inherently uncertain outcomes. In particular, we look to guidelines for designing interfaces for artificial intelligence (AI) applications that are based on fundamental findings from related domains such as psychology and law. Design guidelines for AI applications, while new, follow a decades-long intellectual tradition from human-computer interaction community. From Neilsen's heuristics for user interfaces [62] to Norman's principles of designs of everyday objects [64], guidelines have aided practitioners in designing interfaces and sparked future research.

This paper offers similar design guidelines for investing apps to encourage healthier investing behaviors over market speculation. Our guidelines are based on fundamental insights from three bodies of related work: 1) findings from household finance and economics literature on healthy investing, 2) the dual process theory from behavioral sciences, and 3) design metaphors used in interfaces with uncertain rewards. These disparate insights were clustered into eight actionable guidelines that can help encourage more successful investing behaviors among the users of these platforms. We validate the guidelines by using them to analyse two 
popular US trading apps, Robinhood and E-Trade. We end the paper by discussing design implications and opportunities for future design.

This paper makes three contributions: first, it demonstrates, based on fundamental research from related domains how investing apps might encourage certain kinds of investing behaviors. Second, it introduces a set of design guidelines for investing apps that may encourage more successful investing behaviors. Finally, it identifies opportunities for design and research by highlighting gaps in current implementations of investing apps.

\section{RELATED WORK}

This paper tackles a topic that is inherently interdisciplinary. As such, it is informed by empirical observations that investment outcomes for retail investors are dominated by behavioral decisions rather than information, theoretical models that explain these behaviors, and by previous approaches of designing guidelines.

\subsection{Behavior of Retail Investors}

In practice, most retail investors underperform their professional counterparts, even when they have the same information. Researchers have attributed this underperformance primarily to behavioral factors. Overconfidence in their investing decisions, poor risk evaluation [8,31], overreacting to news events [54], and believing they can predict the market $[46,47]$ lead retail investors to realize fewer gains.

Because underperformance is caused by behavioral factors, rather than informational factors, making trading easier or increasing access to information backfires. Indeed, it encourages investors to trade more actively and perform even worse $[9,65]$. Some popular media accounts also contend that easier app-initiated trading nudges retail investors to take bigger risks [71, 72, 92, 93]. However, outside of accounts in popular media, research on how these apps influence investing behaviors is still lacking. Overall, the empirical research on retail investor outcomes suggests that the design of our guidelines should be informed by behavioral findings on financial decision-making.

\subsection{Heuristic Evaluation Processes}

Many studies have shown that decision making under uncertainty, such as in financial markets, involves heuristic processing [70, 82]. Unlike systematic processing that involves careful and deliberate processing of the message, heuristic processing reduces cognitive effort by using simple decision rules to quickly analyze situations. While these simplifications, such as buying stocks based on a friend's recommendation, are often valuable in uncertain environments, they are also susceptible to predictable biases. For instance heuristic decisions are prone to persuasive techniques such as framing, anchoring, and social proof [21, 32, 52, 56, 82-84]. These effects are further intensified in digital settings $[18,51,96]$. Overall, this research suggests that design metaphors and decisions that affect heuristic processing can be leveraged to improve trading habits and thus outcomes for investors. We focus our attention next to such design metaphors.

\subsection{Design Metaphors}

User interface choices such as what elements are first visible, which stimuli are salient (e.g. choice of colors), and which settings are chosen as defaults, influence the heuristic decisions made by users [50]. Similarly, researchers have studied how design metaphors can make messages more persuasive $[29,56]$. Others note that certain design patterns (dark patterns) can encourage heuristic processing and result in more instinctive decision making [12].

Most closely related to our work, Tanakaa and Kawabatab found the interface predictability can impact the kinds of bets people make [81]. To our knowledge, no prior work has directly studied how design metaphors influence trading habits. However, other researchers have studied the impact of design metaphors in contexts such as filing taxes [40], social lending [94], and voting [42]. We leverage these findings taken together in developing our guidelines.

\subsection{Guidelines for Designing Human-Centered Technology}

For several decades, the human-computer interaction community has proposed guidelines for ethical design of technology across many domains. For instance, Norman applied principles of designs from everyday objects to technology products [64]. Höök's concept of soma design shifted the perspective on interactive design to focus more on fundamental human values [35]. Horvitz's formative work on mixed-initiative systems [36], Brown's work on human-computer interfaces [16], and Amershi et al.'s work on human-AI interaction guidelines [4] are some example of sets of guidelines that serve as a useful resource for practioners working with consumer-focused technology. There is also a growing body of research on how and why to improve the fairness and explanability of AI systems [45, 49, 73, 85]. Several notable organizations such as Google [1], McKinsey [17], and Partnership on AI [2] have also laid down their own principles for responsibly building AI products. Further, there has also been work on how to best operationalize these guidelines in industry $[53,58]$.

The development of design guidelines generally follows a fourstep process that we adopt in our own work: 1) a review of findings from fundamental research to suggest possible design decisions or metaphors, 2) clustering of related decisions and abstracting higherlevel guidelines, 3) evaluation of guidelines to ensure they apply to practical design artifacts, and 4) refinement based on evaluation.

While guidelines are meant to distill theoretical rigor into practical suggestions, they are not meant to be rigid rules. Also, given the effort and time required to design new interfaces, it remains difficult in practice to evaluate if designers' decisions based on guidelines empirically improve user outcomes. Indeed, some of the most impactful guidelines such as Neilsen's heuristic evaluation method [62] or Amershi et al's guidelines for human-AI interaction [4] lacked such evaluation when they were first introduced. Our work has the same limitation.

Finally, we note that a theory-based approach is not the only feasible way to discover design guidelines. For instance, a service design approach has also been successfully used in the area of financial literacy [97] and it is possible such an approach might unearth new service expectations. Elsewhere, Odom et al. offer deep design 
guidance on "slow technology" using a research through design approach [66, 67]. It is easy to see how such an approach might also be valuable around investing. Further afield, Irani and others take an ethnographic approach that critically examines power structures [38]. While our work is largely complementary to these methodologies, this prior work also highlights our own methodological limitations. For instance, we do not seek to question or reframe the goals of retail investing or to investigate the power structures inherent in app-initiated investing.

\section{METHODS}

We developed the guidelines in Table 2 using a four-phase process. In Phase 1, we reviewed fundamental literature from behavioral finance, psychology, and design relevant to financial decision making and tried to extract recommendations that are actionable through interaction design interventions. In Phase 2, we consolidated these insights to propose an initial list of design guidelines for investing apps. In Phase 3, we applied these guidelines to one trading app (Robinhood) and one traditional online brokerage (E-Trade) to evaluate their applicability, violations, and blindspots and asked other researchers in our organization with no prior experience designing investing interfaces to independently review the guidelines and their applications. These reviews led to improvements to enhance the clarity and scope of the guidelines in Phase 4.

\section{PHASE 1: REVIEW OF FUNDAMENTAL THEORY}

\subsection{Investing, Uncertainty, and Diversification}

Investing is the act of putting aside money with the hope of gaining more, while acknowledging that they also stand to lose their capital. This inherent risk associated with investing sets it apart from saving, which could be practically "risk-free" [25]. The expected returns on investments are generally understood to be determined by three factors: asset allocation (the kinds of things or assets that are invested in, such as stocks, real estate, etc.), security selection (the particular assets or securities chosen, such as specific companies, plots of land, etc.), and time horizon (the timeline of when these securities are bought and sold) [28]. The expected return from particular allocations, securities, and timing are subject to risk. Risk is generally classified as either systematic or specific. Systematic risks such as recessions, interest rate changes, pandemics, etc. broadly affect all investing (e.g. most investments do poorly in a shrinking economy). Specific risks are related to a particular security or industry.

4.1.1 Diversification. Diversification is the process of investing in multiple kinds of assets and securities and with varying timing to reduce the specific risk assumed [60]. Investing and portfolio theory emphasizes diversification, but empirically there is a large gap between these theoretical recommendations and how retail investors actually invest $[8,27]$. While adequate diversification is possible even with 30 securities [78], retail investors typically only invest in 4 [8]. In addition, many retail investors trade speculatively rather than systematically and so increase risks related to timing. As a result of these actions, an average retail investor underperforms institutional investors such as university endowments by 4 to $8 \%$ every year [48], and even the market as a whole by approximately $1.5 \%$.
4.1.2 Security Selection. While portfolio theory suggests choosing securities based on expectations of future earnings and growth potential, other factors are empirically more predictive of retail security selection. In particular, retail investors choose securities with a local bias and are overweight past performance.

Local bias is the tendency of investors to invest in stocks of businesses that they are psychologically or physically nearby, such as a local construction company, the industry that employs them, or a favorite chain restaurant. However, the increased familiarity with the selected securities does not predict increased future performance [27, 47]. Such concentrated portfolios can sometimes perform better than diverse portfolios but also carry more specific risk, and underperform over the long term [8].

Kumar and Dhar found that a large number retail investors are sensitive to past price trends [46], such as focusing on stocks that are "rising" or a "steal" at current prices. Retail investors with high trend-tracking behavior were correlated with having portfolios with lower levels of diversification [27].

4.1.3 Market News and Timing. While news releases and earning events have some significance for future returns of an investment, retail investors tend to overreact to these events, believing they fundamentally change the value of their investments more than they actually do [54]. Barbera and Odean found that stocks that retail investors bought tend to earn strong returns in the subsequent two weeks of the trade but underperform in the longer run. This behavioral anomaly of selling investments that are doing well while holding on to their losing investments is called the disposition effect [8]. We outline potential reasons for this bias in Section 4.2.3.

4.1.4 Sensation Seeking. Investing money in the stock market can result in a thrilling sensations akin to gambling. This is evidenced by the fact in periods with high lottery jackpots, the volume of trade is lower [31]. However, high-turnover in portfolios, whether caused by an overreaction to market news or sensation-seeking, decreases investing returns over time. Active retail investors underperform the market by $6.5 \%$ every year, as compared to $1.5 \%$ for investors who buy and hold [8].

4.1.5 Transaction Costs. While transaction costs such as brokerage commissions, taxes, and fees reduce the returns earned by investors, there is evidence that retail investors earn below market returns even before these costs are accounted for [8]. Phone based trading apps and new brokerages typically charge no commissions, and instead earn money through margin fees, cash balance interest, and compensation by other wholesaler firms that buy and sell securities [86]. As a result, investors now can trade securities for free. Such free trades have increased trading frequency [86]. And since underperformance of retail investors is caused by behavioral, rather than informational, factors, more frequent trading tends to exacerbate the problem.

\subsection{Heuristic Evaluation Processes}

The heuristic-systematic model of information processing is a dualprocess theory that suggests that human beings can process messages systematically and/or heuristically [19]. Systematic processing involves careful and deliberate processing of the message, whereas heuristic processing reduces cognitive effort by using simplifying 
decision rules to quickly analyze the message. For instance, heuristic processing might skip the complete processing of the content of the message and instead uses indicators such as credibility and expertise the person who is sending the message or endorsing it. This can occasionally lead to cognitive biases in the decision making process [82].

Investment decisions are made in the presence of heuristic processing [70]. Due to imperfect information in financial markets, inherent uncertainties, and volatility, investors can only rely on a handful of data points when making decisions. Heuristics, such as past performance of a stock or analysts rankings, simplify and speed up the decision-making process. Studies suggest that even financially literate investors are driven by behavioral factors and tend to trust their intuition while building their portfolios [26]. However, relying on some heuristics over others can result in biased judgments and poor financial decisions [3]. For instance, the level of under-diversification is affected by factors such as overconfidence, trend-tracking behavior, and local bias of the investor [27].

The two most important determinants of which processing route is used when processing a information are motivation and ability [69]. People are more likely to engage systematically with a persuasive message if they are more motivated to do so. This in turns depends on the personal relevance and response involvement of the message. Similarly, people's tendency to choose heuristic processing is higher when availability of cognitive resources is low. This includes lack of time, focus, or requisite knowledge or the presence of stress and other distractions [26]. Below, we discuss specific heuristics most relevant to investing, and how they affect financial decisions.

4.2.1 Representativeness Heuristic. Under uncertainty, such as while investing in stocks, people tend to rely on representativeness to make decisions. For instance, trend-tracking investors believe that a stock with a good returns in the past will continue to perform well in the future $[7,14]$. This leads investors to make generalized judgments about the potential of stock after observing its performance for a short period of time. These analyses are prone to be incorrect since the expected price of a company's stock is based on expectations of its future earnings and not necessarily based on past prices.

4.2.2 Availability Heuristic. People assess the likelihood of events with the salience of the event, i.e. the ease at which similar instances can be brought to mind. Investment decisions can be biased by more vivid and memorable movements in stock prices, what other investors are purchasing, and similar salient events rather than less salient information such as the history of dividends paid by the company. The availability heuristic also causes investors to blindly trust analysts' market recommendation revisions, even when they are not sound investments [44].

4.2.3 Hot Hand Fallacy and Gambler's Fallacy. The hot hand fallacy and gambler's fallacy are two widely studied cognitive biases that causes people to misinterpret sequences of essentially random market prices and affects their investment decision. The hot hand fallacy is the expectation that price trends will persist indefinitely, i.e. rising stocks will continue to rise and falling stocks will continue to fall. This leads to buying stocks that show an increasing trend and selling stocks that show a decreasing trend, together increasing the cost of investing. The gambler's fallacy is the expectation that investments will always revert to their previous price, without regard to fundamental changes such as technological innovation or obsolescence. This leads to people holding onto losing investments for too long and selling winning investments too soon. Huber et al. found that people who rely on the recommendations of experts were prone to the hot hand fallacy and people who acted individually were prone to the gambler's fallacy [37].

This disposition effect stems from the prospect theory, which posits that humans tend to be risk-averse when dealing with gains but risk-seeking when dealing with losses [41]. Factors such as involvement, choice, and familiarity can also lead investors to develop an illusion of control and lead them to implicitly believe that they can control the outcome of chance situations [47].

4.2.4 Anchoring Heuristic. The anchoring heuristic is a behavioral bias in which, when under uncertainty, people estimate quantities using an initial benchmark and then adjusting it to make judgments [82]. One consequence of this is that people can anchor their estimates of what an investment is worth to the price they purchased it for rather than to present market conditions. This can cause them to hold onto poor investments for too long $[61,70]$.

4.2.5 Confirmation Bias. Confirmation bias leads people to seek information that is consonant with their prior beliefs. It lead to investors maintaining unrealistically high expectations of performance of their current investments, and lower expectations of alternative investments, leading to lower overall returns [68]. Moreover, focusing too narrowly on ones current portfolio can also expose investors to high levels of specific risk.

\subsection{Design Metaphors}

Beyond fundamental psychological biases, decision-making is also influenced by design metaphors and decisions. Specifically, certain design decisions can prompt System 1 thinking processes, which are undemanding, instinctive, and possibly less rational than System 2 thinking processes as suggested by dual process theories [12, 77]. We outline some relevant decisions below.

4.3.1 Jackpot Metaphors and lgnoring Probabilities. Few investors make investment decisions after accounting for factors such as implied volatility, or adjusting returns for risk [57]. However, when deciding whether to invest in what is perceived as a "jackpot", decision-making is dominated by the magnitude of the potential winning rather than its probability [30]. To the extent that trading apps highlight the massive returns of penny stocks and some options contracts or use explicit visual imagery of jackpots or lotteries (Figure 1) they may encourage investment gains to be perceived as jackpots.

4.3.2 Commitment Leading to Entrapment. Entrapment is the tendency of people to commit to a goal that has not been realized beyond an economically rational point $[15,79]$. Argyris found that cutting ones losses, in gambling and trading, is interpreted as embarrassing and also giving up on potential returns [6]. To the extent that apps and platforms allow users to share information about 
Table 1: Initial clusters of design guidelines for investing apps. Guidelines are inspired by research done by visual design (V), behavioral sciences $(B)$, and finance $(F)$ communities.

\begin{tabular}{|l|l|}
\hline Factor & Guideline \\
\hline [F] Diversification & Encourage Diversification \\
\hline [B] Security Selection & \\
[B] Anchoring Heuristic & Focus on the Long-Term Future \\
[B] Commitment Leading to Entrapment & \\
[F] Market Timing & \\
\hline [B] Hot Hand Fallacy & Do Not Encourage Predicting Random Numbers \\
[B] Gambler's Fallacy & \\
[B] Confirmation Bias & \\
\hline [V] Gratification Delays & Discourage Active Trading \\
[V] Habit Formation & \\
[F] Sensation Seeking & \multirow{2}{*}{ Do Not Make Trading a Popularity Contest } \\
[V] Ignoring Probability & \\
[B] Availability Heuristic & \\
[F] Market News & Encourage Thoughtful Trading \\
\hline [V] Reinforcement Schedules & Minimize Roundtrip Costs \\
\hline [B] Transaction Costs & \\
\hline
\end{tabular}

their trade, such as on a social feed, they may increase commitment, in turn leading to entrapment, despite mounting losses [90].

4.3.3 Gratification Delays, Reinforcement Schedules and Habit Formation. While latency in interfaces is generally detrimental [5], immediate payback of risky bets encourages more frequent plays and the tendency to regamble any winnings with little rational financial consideration [30]. For instance, when playing with scratchcards and slot machines, there is only a few seconds between the initial gamble and the payback. Instant settlement on trading apps can also potentially result in similar behavior.

How frequently and regularly rewards are obtained can play a significant role in engendering behaviors and habit formation. A variable-ratio reinforcement schedule, where rewards result after a varying number of attempts, such as with slot machines, lead to stronger habit formation [24]. Unfortunately, frequent trading, especially with little financial consideration, results in rewards with varying frequency, further reinforcing the risky habit.

\section{PHASE 2: CLUSTERING OF GUIDELINES}

From the literature review phase, we came up with a list of 25 factors that play a role in determining investors' success. Of these, 20 factors can be affected through design decisions. For instance, even though overconfidence works to the detriment of retail investors, reducing overconfidence is hard to do through interface design. We labeled these relevant factors as either visual, behavioral, or financial, depending on the community where the underlying research was conducted.

Next, one member of the team generated an initial set of design guidelines that operationalized these factors. The candidate guidelines were then clustered using affinity diagramming, such that guidelines that were related in possible implementations and effect were clustered together. We limited cluster sizes such that guidelines did not become too abstract and distinguishing between applications and violations of the guidelines was difficult to identify.

This clustered set of guidelines went through multiple stages of iterations. This involved reclustering, rephrasing, and dropping some guidelines. For instance, we realized that frequency and thoughtful trading were not necessarily correlated, so we split the "Encourage Infrequent and Thoughtful Trading" guideline into two. We also noticed that the "Do Not Charge Commissions" guideline emphasized a particular business decision rather than a design decision. We rephrased this guideline to "Minimize Roundtrip Costs" to improve its applicability and flexibility. Other guidelines were rephrased to improve clarity. Still other guidelines were dropped entirely if they did not relate specifically to investment or trading, for instance the "Use Clear Verbiage" guideline.

Some of harder to resolve conflicts come from inconsistencies across the different domains. As one notable example, though finance literature suggests transaction costs significantly bite into an investor's returns, behavioral finance literature suggests that the lack of commissions can encourage investors to trade more frequently. In this case, we decided to keep both the, potentially conflicting, guidelines. This was in recognition of the fact that technology design can involve difficult trade-offs. Our set of guidelines helps designers evaluate their design choices, and consider how problematic effects could be mitigated creatively. A list of the clusters and corresponding guidelines towards the end of this phase is shown in Table 1. 


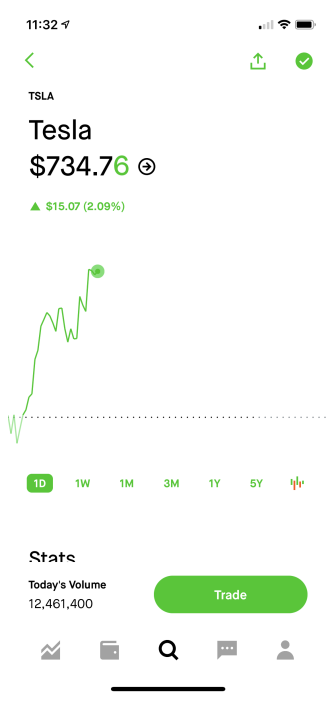

(a) Robinhood highlights short-term performance. Violates V1 and B4.

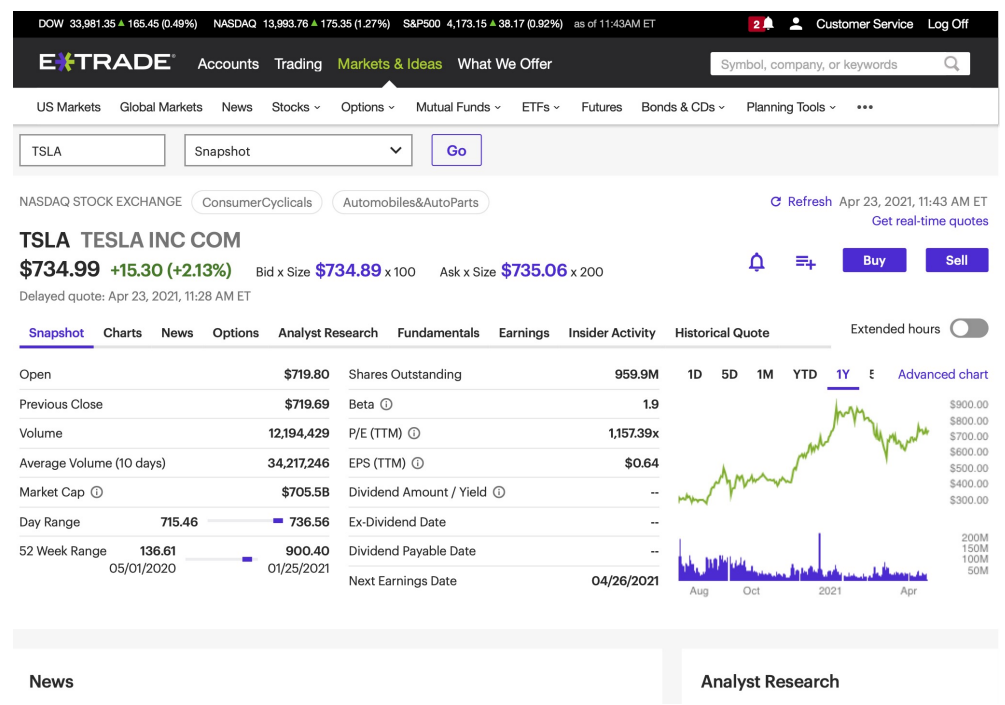

(b) E-Trade exposes long-term trends and highlights useful metrics. Applies V1, V2, B2, and B3.

Figure 2: Examples of investing apps evaluated in Phase 3 of the study and evaluators' feedback on how they apply and violate our guidelines. Images from the authors' accounts on each platform.

\section{PHASE 3: EVALUATION}

In this phase, we evaluated our set of guidelines with five other researchers and designers to identify its applications, violations, and blind spots. Two of the evaluators had not used any trading app in the past. All of them are members of the Human-Computer Interaction Institute at Carnegie Mellon University and are our frequent collaborators. Protocol for the study was approved by Carnegie Mellon University's IRB.

Our study was inspired by the modified heuristic evaluation done by Amershi et al. while devising their list of guidelines for human-AI interaction [4]. Amershi et al. ask evaluators to use their guidelines to assess existing interfaces and identify applications and violations of their guidelines. We extended their method and also asked evaluators to also provide feedback on any potential blind spots of the guidelines themselves. This helped us identify potential ways in which our guidelines could be extended to be more applicable.

For our evaluation, we decided to study the design patterns in two different trading platforms: Robinhood, one of the most popular zero-commission trading apps, and E-Trade, one of the "big four" brokerages in the United States. Between them, these platforms handle more than 5 million daily average revenue trades [74]. Moreover, these two platforms use significantly differently modalities (smartphone and website, respectively) and target investors with different amounts of investable capital, allowing us to inspect how our guidelines evaluates them differently. If the evaluator did not have an account on the platform, we provided them a comprehensive list of screenshots and flows of the application as shown in Figure 2. Evaluators provided verbal feedback on how each platform compared against our set of guidelines and how easy and intuitive it was to apply the guidelines.
Evaluators were able to identify applications, violations, and blind spots of guidelines, despite not having prior experience designing trading platforms. The cumulative data is presented in Table 2. For brevity, the table displays the updated text of the guidelines from the end of Phase 4.

\section{PHASE 4: REVIEW OF REVISIONS}

In Phase 4, we incorporated evaluators' feedback by revising the guidelines. First, we rephrased the "Encourage Thoughtful Trading" guideline to "Encourage Deliberate Trading" to clarify the emphasis on deliberation and systematic processing. We also improved the order in which the guidelines were presented to make them easier to follow. They were numbered and labeled with the overarching research community they were inspired from (visual, behavioral, or financial) and sorted by type. We also ensured our final guidelines obeyed the phrasing conventions used by Amershi et al. [4]. These included limiting each guidelines to 10 words, without any conjunctions, and beginning with an action word. We also added a description to help clarify any potential ambiguities. This process resulted in the eight guidelines as seen in Table 2.

\subsection{Limitations}

The list of factors we were able to extract from Phase 1 is nonexhaustive. While our factors were the most prominent in the literature we reviewed, many other visual, behavioral, and financial factors may affect an investor's success in investing. Furthermore, the factors we extracted are limited to the extent we reviewed the literature. This is particularly challenging due to the interdisciplinary nature of investment and the many fields of expertise that may be relevant. Finally, some factors such as risk appetite and political inclination yield inconsistent or even contradictory guidance. 
Table 2: Design guidelines for investing apps that encourage healthy investing behaviors. Guidelines are roughly split into visual design (V1 and V2), behavioral (B1 to B5), and financial (F1).

\begin{tabular}{|c|c|c|c|}
\hline \multicolumn{2}{|r|}{ Guideline } & \multirow[b]{2}{*}{$\begin{array}{l}\text { Robinhood } \\
\text { Prominently features performance } \\
\text { charts while all information rele- } \\
\text { vant to future performance is below } \\
\text { the fold. }\end{array}$} & \multirow[b]{2}{*}{$\begin{array}{l}\text { E-Trade } \\
\text { Easy access to metrics such as an- } \\
\text { alyst recommendations, price tar- } \\
\text { gets, income statements, etc. in ad- } \\
\text { dition to past performance. }\end{array}$} \\
\hline V1 & $\begin{array}{l}\text { Focus on the Potential Instead of the Past } \\
\text { Display information that helps investors make in- } \\
\text { vestment decisions based on how the security will } \\
\text { perform in the future, not how it has performed in } \\
\text { the past. }\end{array}$ & & \\
\hline V2 & $\begin{array}{l}\text { Expose Risks } \\
\text { Help the investors understand exactly what they } \\
\text { stand to lose or gain with the investments they make. }\end{array}$ & $\begin{array}{l}\text { Highlights the systematic risks of } \\
\text { investing in the stock market but } \\
\text { not specific risks for individual se- } \\
\text { curities. }\end{array}$ & $\begin{array}{l}\text { Provides tools to calculate probabil- } \\
\text { ity of a security reaching a certain } \\
\text { price by a certain date. Displays } \\
\text { beta values. }\end{array}$ \\
\hline B1 & $\begin{array}{l}\text { Encourage Diversification } \\
\text { Help investors put their money in a variety of finan- } \\
\text { cial instruments and industries. }\end{array}$ & $\begin{array}{l}\text { Each } \\
\text { diver } \\
\text { data }\end{array}$ & $\begin{array}{l}\text { Shows the asset composition of a } \\
\text { portfolio and compares it to sample } \\
\text { portfolios. Security selection met- } \\
\text { rics are missing. }\end{array}$ \\
\hline B2 & $\begin{array}{l}\text { Deliberate Trading } \\
\text { sy for investors to make well-tho } \\
\text { d on knowledge of market funda }\end{array}$ & $\begin{array}{l}\text { One-click access to trading allows } \\
\text { making trades despite lack of time, } \\
\text { focus, or background or in the pres- } \\
\text { ence of stress and other distrac- } \\
\text { tions. }\end{array}$ & $\begin{array}{l}\text { The website modality and interface } \\
\text { complexity forces investors to take } \\
\text { their time while making trades. Or- } \\
\text { ders can be saved for later. }\end{array}$ \\
\hline B3 & $\begin{array}{l}\text { Encourage Long-Term Trading } \\
\text { Help investors think of trading as a long-term activity } \\
\text { and discourage them from trying to catch minute-to- } \\
\text { minute market movements. }\end{array}$ & $\begin{array}{l}\text { Default time range in charts is one } \\
\text { day, which can incentivize trying to } \\
\text { catch the day-to-day market move- } \\
\text { ments. }\end{array}$ & $\begin{array}{l}\text { Default time range in } \\
\text { the order of years. Gai } \\
\text { fied as long and short }\end{array}$ \\
\hline B4 & $\begin{array}{l}\text { Discourage Active Trading } \\
\text { Limit investors' ability making frequent trades unless } \\
\text { they understand risks associated with it. }\end{array}$ & $\begin{array}{l}\text { Proceeds from sale are instantly } \\
\text { immediately available to reinvest. } \\
\text { Obeys SEC-mandated day trade re- } \\
\text { strictions. }\end{array}$ & $\begin{array}{l}\text { Trades take upto } 2 \text { days to set- } \\
\text { tle for cash accounts. Obeys SEC- } \\
\text { mandated pattern day trade restric- } \\
\text { tion for margin accounts. }\end{array}$ \\
\hline B5 & $\begin{array}{l}\text { Discourage Overreactions to Market News } \\
\text { Help investors interpret market news in a manner } \\
\text { consistent with market fundamentals instead of act- } \\
\text { ing on hype and behavioral factors. }\end{array}$ & $\begin{array}{l}\text { Prominently features market news. } \\
\text { Sends push notifications close to } \\
\text { earning events. Highlights securi- } \\
\text { ties whose price moved the most. }\end{array}$ & $\begin{array}{l}\text { Market news and top movers list is } \\
\text { available but not the centerpiece of } \\
\text { the home screen. }\end{array}$ \\
\hline F1 & $\begin{array}{l}\text { Minimize Roundtrip Costs } \\
\text { Minimize the amount investors have to pay for each } \\
\text { trade in transaction costs and ensure these are trans- } \\
\text { parent to the user. }\end{array}$ & $\begin{array}{l}\text { Does not charge commissions or } \\
\text { transaction fees for any type of se- } \\
\text { curity. }\end{array}$ & $\begin{array}{l}\text { Does not charge commissions or } \\
\text { transaction fees for most securities. } \\
\text { Some contracts have a flat fee. }\end{array}$ \\
\hline
\end{tabular}

In evaluating our guidelines, we were only able to examine two investing apps that are popular in the US market. Unlike applications that are ready to use as soon as they are installed, trading platforms require providing sensitive personal information and making a financial commitment. Similarly, we were unable to assess our guidelines against non-American investing apps such as eToro (popular in UK and Israel) because we could not open trading accounts on these platforms from the US.

Furthermore, while we conducted our evaluation with humancomputer interaction researchers and designers knowledgeable about the design process in general, we are missing two important voices: of financial experts and of users of investing apps. Since we were unable to recruit anyone from the financial services industry or do any qualitative work, it is hard to judge whether our guidelines will be effective in nurturing healthy trading habits in practice.

\section{DESIGN IMPLICATIONS}

\subsection{New Interaction Models for Investing}

The above guidelines may be useful not only for evaluating existing trading interactions but also new and emergent ones. For instance, consider Public, a trading app focused on making investing in the stock market "social". Public allows users to display their portfolio on their profile, and share their investment decisions with their friends (Figure 3a). It also curates lists of some of the most popular stocks among users of the app. These features capitalize on the availability heuristic and can potentially make investing a popularity contest; violating guidelines B2, B4, and B5. In contrast, Options AI includes data-driven visualizations of potential future values of a stock based in part on the prices of options sold on the stock (Figure 3b). Such an interface is in line with guidelines V1, V2, and B5.

Designers may also find guidelines useful in adopting ideas from other kinds of applications. For instance, mindfulness applications 


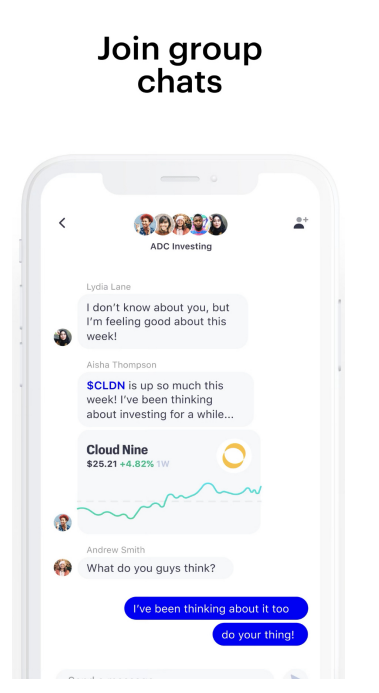

(a) Public turns the stock market into a social activity. Violates B2, B4, and B5.

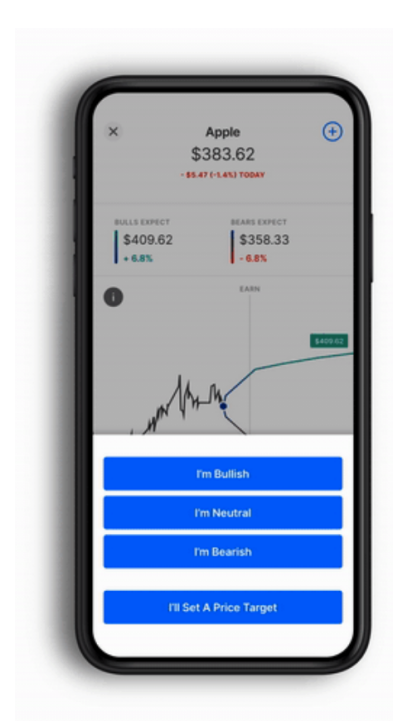

(b) Options AI offers data-driven charts of a security's potential to influence trades. Applies V1, V2, and B5.

Figure 3: Examples of some other investing apps and how they apply and violate our guidelines. Images from each platform's website and marketing materials.

may offer multiple design patterns to encourage deliberate trading (B2), remove fixation on past performance (V1), and discourage overreactions to news (B5).

\subsection{Applications Beyond Investing}

While we developed our guidelines with the assumption that investments were in traditional asset classes such as stocks, bonds, and other regulated securities, they may apply equally well to newer, alternative investments. For instance, a cursory review of app stores for the Apple and Google's mobile platforms surfaces apps for speculating in cryptocurrencies such as Bitcoin (Figure 4a), equity crowdfunding, which allows low-cost investing in startup companies (Figure 4b), and even "democratized" investing in art that allows users to purchase fractions of famous pieces of artwork (Figure 4c). While the markets targeted are varied, guidelines based on fundamental findings may still be relevant.

\section{CONCLUDING DISCUSSION}

We reviewed fundamental literature from the fields of finance, psychology, and design to come up with eight actionable design guidelines for retail investing applications. These efforts, and their subsequent evaluation, suggest that our guidelines can be useful in evaluating trading applications and recommend directions to improve the design of these applications.

\subsection{Non-prescriptive Guidelines}

This research was inspired by media accounts of retail investors suffering catastrophic harm as a result of poor investments. As such, we hypothesized that simple design guidelines might prevent such failures. However, our research suggests that designers, even relying on the most robust theoretical findings, must make tradeoffs. Consequently, our guidelines are non-prescriptive as well. Factors such as the age of the target user, their risk appetite, prior experience with losses in investing, etc. may guide practitioners in making these trade-offs.

We also recognize that our guidelines, while theoretically sound, might be difficult to realize into actual products due to practical business concerns. For instance, companies whose revenues are driven by active trading may find it difficult to discourage the practice. Similarly, though not charging commissions can minimize roundtrip costs, it requires platforms to turn to more creative revenue streams, which have had mixed success so far [89]. While these concerns are beyond the scope of this paper and our own expertise, developing sustainable business practices around these guidelines may be a productive area for future work.

\subsection{Applicability to Vulnerable Populations}

One side-effect of our approach is that our guidelines are likely less effective for vulnerable populations. This is because of persistent population biases in the literature that we draw from, especially psychology [33, 80]. Many fundamental results were studied with white, rich, educated, and independent people [33], and wealth, independence, and education may well affect investing decisions. As such, our guidelines are best seen as the first step in a longer process of making investing more democratic in actuality, not just in rhetoric.

\subsection{Future Work}

Future research could explore the uses and value of these guidelines at various stages of design, and for specific populations. We also see a need for triangulation of guidance from literature with more 


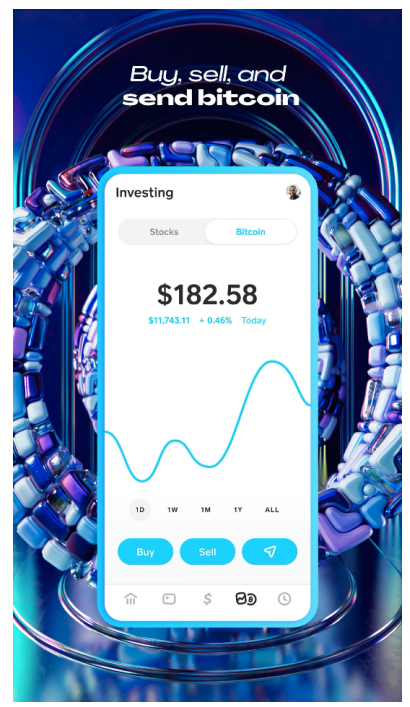

(a) Cash App allows retail investing in Bitcoin.

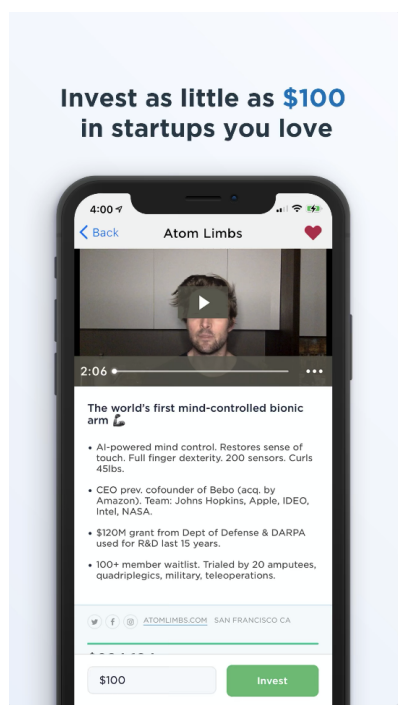

(b) Wefunder allows small investments in non-public companies.

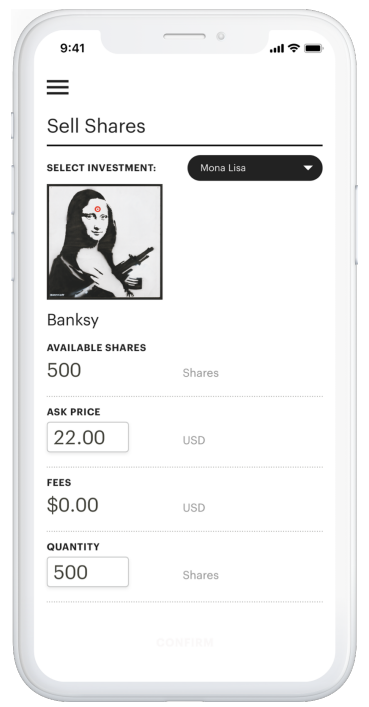

(c) Masterworks allows retail investing in artwork.

Figure 4: Some alternative investment platforms where our guidelines may be applicable. Images from each platform's website and marketing materials.

qualitative and ethnographic methods. For future practice, beyond the direct implications of our work, our guidelines may also serve as a useful starting point for discussions such as how trading apps can encourage deliberate trading. Finally, our work may suggest future policy that requires trading platforms to disclose not only whom they serve, such as the investors with high net worth as is current practice, but also interactional patterns of public interest, such as how long users hold securities, how frequently they trade in response to news events, and the degree of diversification. Similarly, data sharing around interactions like whether investors who received free stocks when joining the platform take greater risks may improve future design.

Overall, our work suggests that investing is an activity worthy of attention from designers and design researchers; and doing so is necessary to transform investing from an activity fraught with risks and reserved to those with privilege into one that is truly democratic.

\section{ACKNOWLEDGMENTS}

We would like to thank Pranav Khadpe, Julia Cambre, and Yasmine Kotturi for insightful discussions and their support. We thank the reviewers for their helpful comments and suggestions. This article solely reflects the opinions and conclusions of its authors and not any individuals named in these acknowledgements, funding agency, or supporting organization.

\section{REFERENCES}

[1] [n.d.]. Our Principles. https://ai.google/principles/

[2] [n.d.]. Tenets. https://www.partnershiponai.org/tenets/

[3] Maqsood Ahmad, Syed Shah, and Faisal Mahmood. 2018. Heuristic biases in investment decision-making and perceived market efficiency: A survey at the Pakistan stock exchange. Qualitative Research in Financial Markets 10 (01 2018), 00-00. https://doi.org/10.1108/QRFM-04-2017-0033
[4] Saleema Amershi, Dan Weld, Mihaela Vorvoreanu, Adam Fourney, Besmira Nushi, Penny Collisson, Jina Suh, Shamsi Iqbal, Paul N Bennett, Kori Inkpen, et al. 2019. Guidelines for human-AI interaction. In Proceedings of the 2019 chi conference on human factors in computing systems. 1-13.

[5] Ioannis Arapakis, Xiao Bai, and B. Barla Cambazoglu. 2014. Impact of Response Latency on User Behavior in Web Search. In Proceedings of the 37th International ACM SIGIR Conference on Research \& Development in Information Retrieval (Gold Coast, Queensland, Australia) (SIGIR '14). Association for Computing Machinery, New York, NY, USA, 103-112. https://doi.org/10.1145/2600428.2609627

[6] Chris Argyris. 1990. The dilemma of implementing controls: the case of managerial accounting. In Readings in accounting for management control. Springer, 669-680.

[7] Waqar Badshah, Shoaib Irshad, and Usman Hakam. 2016. Effect of Representativeness Bias on Investment Decision Making. (01 2016).

[8] Brad M Barber and Terrance Odean. 2013. The behavior of individual investors. In Handbook of the Economics of Finance. Vol. 2. Elsevier, 1533-1570.

[9] Brad M. Barber and Terrance Odean. 2015. Online Investors: Do the Slow Die First? The Review of Financial Studies 15, 2 (06 2015), 455-488. https://doi.org/10.1093/rfs/15.2.455 arXiv:https://academic.oup.com/rfs/articlepdf $/ 15 / 2 / 455 / 24432450 / 150455 . p d f$

[10] Belén Barros Pena, Bailey Kursar, Rachel E. Clarke, Katie Alpin, Merlyn Holkar, and John Vines. 2021. "Pick Someone Who Can Kick Your Ass" - Moneywork in Financial Third Party Access. Proc. ACM Hum.-Comput. Interact. 4, CSCW3, Article 218 (Jan. 2021), 28 pages. https://doi.org/10.1145/3432917

[11] Jamil Baz, Josh Davis, Cristian Fuenzalida, and Jerry Tsai. 2020. Method in the Madness: Bubbles, Trading, and Incentives. The fournal of Portfolio Management 46, 8 (2020), 27-33.

[12] Christoph Bösch, Benjamin Erb, Frank Kargl, Henning Kopp, and Stefan Pfattheicher. 2016. Tales from the dark side: Privacy dark strategies and privacy dark patterns. Proceedings on Privacy Enhancing Technologies 2016, 4 (2016), 237-254.

[13] Michael Bossetta. 2018. The Digital Architectures of Social Media: Comparing Political Campaigning on Facebook, Twitter, Instagram, and Snapchat in the 2016 U.S. Election. fournalism \& Mass Communication Quarterly 95, 2 (2018), 471-496. https://doi.org/10.1177/1077699018763307 arXiv:https://doi.org/10.1177/107769901876330

[14] Ramzi Boussaidi. 2013. Representativeness Heuristic, Investor Sentiment and Overreaction to Accounting Earnings: The Case of the Tunisian Stock Market. Procedia - Social and Behavioral Sciences 81 (2013), 9 - 21. https://doi.org/10.1016/ j.sbspro.2013.06.380 World Congress on Administrative and Political Sciences.

[15] Joel Brockner, Jeff Greenberg, Audrey Brockner, Jenny Bortz, Jeanette Davy, and Carolyn Carter. 1986. Layoffs, equity theory, and work performance: Further evidence of the impact of survivor guilt. Academy of Management journal 29, 2 (1986), 373-384. 
[16] C.M. Brown. 1999. Human-computer Interface Design Guidelines. Intellect. https //books.google.com/books?id=b2FphAxqIYIC

[17] Roger Burkhardt, Nicolas Hohn, and Chris Wigley. 2019. Leading your organization to responsible AI. https://www.mckinsey.com/business-functions/mckinseyanalytics/our-insights/leading-your-organization-to-responsible-ai

[18] Ryan Calo. 2013. Digital market manipulation. Geo. Wash. L. Rev. 82 (2013), 995.

[19] Shelly Chaiken. 1980. Heuristic versus systematic information processing and the use of source versus message cues in persuasion. Fournal of personality and social psychology 39, 5 (1980), 752.

[20] Edward Chancellor. 1999. Devil take the hindmost: A history of financial speculation. (1999).

[21] Robert B Cialdini. 2009. Influence: Science and practice. Vol. 4. Pearson education Boston, MA.

[22] Michael Dickard. 2020. Cognitive Biases in Retail Investor Decision Making and HCI: A Research Agenda. (2020).

[23] Chris Elsden, Tom Feltwell, Shaun Lawson, and John Vines. 2019. Recipes for Programmable Money. In Proceedings of the 2019 CHI Conference on Human Factors in Computing Systems (Glasgow, Scotland Uk) (CHI '19). Association for Computing Machinery, New York, NY, USA, 1-13. https://doi.org/10.1145/ 3290605.3300481

[24] Charles B Ferster and Burrhus Frederic Skinner. 1957. Schedules of reinforcement (1957).

[25] William E Fruhan et al. 1992. Diversification, the Capital Asset Pricing Model, and the Cost of Equity Capital. Case Problems in Finance (1992), 407-20.

[26] Markus Glaser and Torsten Walther. 2013. Run, Walk, or Buy? Financial Literacy, Dual-Process Theory, and Investment Behavior. SSRN Electronic fournal (03 2013). https://doi.org/10.2139/ssrn.2167270

[27] William N Goetzmann and Alok Kumar. 2008. Equity portfolio diversification Review of Finance 12, 3 (2008), 433-463.

[28] Benjamin Graham, David L. Dodd, and Warren Buffett. 2009. Security analysis: principles and technique. McGraw-Hill.

[29] Colin M Gray, Yubo Kou, Bryan Battles, Joseph Hoggatt, and Austin L Toombs. 2018. The dark (patterns) side of UX design. In Proceedings of the $2018 \mathrm{CHI}$ Conference on Human Factors in Computing Systems. 1-14.

[30] Mark Griffiths and Richard Wood. 2008. The psychology of lottery gambling. International Gambling Studies 1 (02 2008), 27-45. https://doi.org/10.1080/ 14459800108732286

[31] Mark Grinblatt and Matti Keloharju. 2009. Sensation seeking, overconfidence, and trading activity. The fournal of Finance 64, 2 (2009), 549-578.

[32] Jon D Hanson and Douglas A Kysar. 1999. Taking behavioralism seriously: The problem of market manipulation. NYUL Rev. 74 (1999), 630.

[33] Joseph Henrich, Steven J Heine, and Ara Norenzayan. 2010. The weirdest people in the world? Behavioral and brain sciences 33, 2-3 (2010), 61-83.

[34] Tory Hobson. 2018. Gamification in the Most Delightful Way. https://medium com/pinch-pull-press/gamification-in-the-most-delightful-way- 504 caf72c1bc

[35] K. Höök. 2000. Steps to take before intelligent user interfaces become real. Interact Comput. 12 (2000), 409-426.

[36] Eric Horvitz. 1999. Principles of mixed-initiative user interfaces. In Proceedings of the SIGCHI conference on Human Factors in Computing Systems. 159-166.

[37] Jürgen Huber, Michael Kirchler, and Thomas Stöckl. 2010. The hot hand belief and the gambler's fallacy in investment decisions under risk. Theory and decision 68, 4 (2010), 445-462.

[38] Lilly C Irani and M Six Silberman. 2013. Turkopticon: Interrupting worker invisibility in amazon mechanical turk. In Proceedings of the SIGCHI conference on human factors in computing systems. 611-620.

[39] Anthony Jameson, Bettina Berendt, Silvia Gabrielli, Federica Cena, Cristina Gena, Fabiana Vernero, and Katharina Reinecke. 2014. Choice architecture for humancomputer interaction. Foundations and Trends in Human-Computer Interaction 7 , 1-2 (2014), 1-235.

[40] Paul Kiel Justin Elliott. 2019. Inside TurboTax's 20-Year Fight to Stop Americans From Filing Their Taxes for Free. https://www.propublica.org/article/insideturbotax-20-year-fight-to-stop-americans-from-filing-their-taxes-for-free

[41] Daniel Kahneman and Amos Tversky. 1979. Prospect Theory: An Analysis of Decision under Risk. Econometrica 47, 2 (1979), 263-291. http://www.jstor.org/ stable/1914185

[42] Gabriel Katz, R Michael Alvarez, Ernesto Calvo, Marcelo Escolar, and Julia Pomares. 2011. Assessing the impact of alternative voting technologies on multiparty elections: Design features, heuristic processing and voter choice. Political Behavior 33, 2 (2011), 247-270.

[43] Joseph Jofish Kaye, Mary McCuistion, Rebecca Gulotta, and David A. Shamma 2014. Money Talks: Tracking Personal Finances. In Proceedings of the SIGCHI Conference on Human Factors in Computing Systems (Toronto, Ontario, Canada) (CHI '14). Association for Computing Machinery, New York, NY, USA, 521-530. https://doi.org/10.1145/2556288.2556975

[44] Doron Kliger and Andrey Kudryavtsev. 2010. The Availability Heuristic and Investors' Reaction to Company-Specific Events. Fournal of Behavioral Finance 11, 1 (2010), 50-65. https://doi.org/10.1080/15427561003591116 arXiv:https://doi.org/10.1080/15427561003591116
[45] Todd Kulesza, Margaret Burnett, Weng-Keen Wong, and Simone Stumpf. 2015. Principles of Explanatory Debugging to Personalize Interactive Machine Learning. In Proceedings of the 20th International Conference on Intelligent User Interfaces (Atlanta, Georgia, USA) (IUI '15). Association for Computing Machinery, New York, NY, USA, 126-137. https://doi.org/10.1145/2678025.2701399

[46] Alok Kumar and Ravi Dhar. 2001. A Non-Random Walk Down the Main Street: Impact of Price Trends on Trading Decisions of Individual Investors. (07 2001).

[47] Ellen J Langer and Jane Roth. 1975. Heads I win, tails it's chance: The illusion of control as a function of the sequence of outcomes in a purely chance task. fournal of personality and social psychology 32, 6 (1975), 951.

[48] Josh Lerner, Antoinette Schoar, and Jialan Wang. 2008. Secrets of the academy: The drivers of university endowment success. Fournal of Economic Perspectives 22, 3 (2008), 207-22.

[49] Brian Y. Lim and Anind K. Dey. 2009. Assessing Demand for Intelligibility in Context-Aware Applications. In Proceedings of the 11th International Conference on Ubiquitous Computing (Orlando, Florida, USA) (UbiComp '09). Association for Computing Machinery, New York, NY, USA, 195-204. https://doi.org/10.1145/ 1620545.1620576

[50] Dan Lockton. 2012. Cognitive biases, heuristics and decision-making in design for behaviour change. Heuristics and Decision-Making in Design for Behaviour Change (August 5, 2012) (2012).

[51] Sheng Luo, Bin Gu, Xingbiao Wang, and Zhaoquan Zhou. 2018. Online Compulsive Buying Behavior: The Mediating Role of Self-control and Negative Emotions. In Proceedings of the 2018 International Conference on Internet and e-Business. 65-69.

[52] Xueming Luo. 2005. How Does Shopping With Others Influence Impulsive Purchasing? Journal of Consumer Psychology 15, 4 (2005), 288-294. https: //doi.org/10.1207/s15327663jcp1504_3

[53] Michael A. Madaio, Luke Stark, Jennifer Wortman Vaughan, and Hanna Wallach. 2020. Co-Designing Checklists to Understand Organizational Challenges and Opportunities around Fairness in AI. In Proceedings of the 2020 CHI Conference on Human Factors in Computing Systems (Honolulu, HI, USA) (CHI '20). Association for Computing Machinery, New York, NY, USA, 1-14. https://doi.org/10.1145/ 3313831.3376445

[54] Reza S. Mahani and Allen M. Poteshman. 2008. Overreaction to stock market news and misevaluation of stock prices by unsophisticated investors: Evidence from the option market. Fournal of Empirical Finance 15, 4 (2008), 635 - 655. https://doi.org/10.1016/j.jempfin.2007.11.001

[55] Annie Massa and Sarah Ponczek. 2020. Robinhood's Addictive App Made Trading a Pandemic Pastime. https://www.bloomberg.com/news/features/2020-1022/how-robinhood-s-addictive-app-made-trading-a-covid-pandemic-pastime

[56] Arunesh Mathur, Gunes Acar, Michael J Friedman, Elena Lucherini, Jonathan Mayer, Marshini Chetty, and Arvind Narayanan. 2019. Dark patterns at scale: Findings from a crawl of $11 \mathrm{~K}$ shopping websites. Proceedings of the ACM on Human-Computer Interaction 3, CSCW (2019), 1-32.

[57] Stewart Mayhew. 1995. Implied Volatility. Financial Analysts Journal 51, 4 (1995), 8-20. https://doi.org/10.2469/faj.v51.n4.1916 arXiv:https://doi.org/10.2469/faj.v51.n4.1916

[58] Margaret Mitchell, Simone Wu, Andrew Zaldivar, Parker Barnes, Lucy Vasserman, Ben Hutchinson, Elena Spitzer, Inioluwa Deborah Raji, and Timnit Gebru. 2019. Model Cards for Model Reporting. Proceedings of the Conference on Fairness, Accountability, and Transparency (Jan 2019). https://doi.org/10.1145/3287560. 3287596

[59] Janet Morrissey. 2017. With No Frills and No Commissions, Robinhood App Takes On Big Brokerages. https://www.nytimes.com/2017/02/18/business/robinhoodstock-trading-app.html

[60] David W Mullins. 1982. Does the Capital Asset Pricing Model Work? Harvard Business Review.

[61] Zain Naqvi, Omer Farooq, Naheed Sultana, and Mariam Farooq. 2017. The impact of heuristics on investment decision and performance: Exploring multiple mediation mechanisms. Research in International Business and Finance 42 (07 2017). https://doi.org/10.1016/j.ribaf.2017.07.010

[62] Jakob Nielsen and Rolf Molich. 1990. Heuristic evaluation of user interfaces. In Proceedings of the SIGCHI conference on Human factors in computing systems. 249-256.

[63] Don Norman. 2004. Affordances and design. Unpublished article, available online at: http://www. jnd. org/dn. mss/affordances-and-design. html (2004).

[64] Don Norman. 2013. The design of everyday things: Revised and expanded edition. Basic books.

[65] Terrance Odean. 1998. Are investors reluctant to realize their losses? The fournal of finance 53, 5 (1998), 1775-1798.

[66] William Odom, Mark Selby, Abigail Sellen, David Kirk, Richard Banks, and Tim Regan. 2012. Photobox: On the Design of a Slow Technology. In Proceedings of the Designing Interactive Systems Conference (Newcastle Upon Tyne, United Kingdom) (DIS '12). Association for Computing Machinery, New York, NY, USA, 665-668. https://doi.org/10.1145/2317956.2318055 
[67] William Odom, Ron Wakkary, Jeroen Hol, Bram Naus, Pepijn Verburg, Tal Amram, and Amy Yo Sue Chen. 2019. Investigating slowness as a frame to design longerterm experiences with personal data: A field study of olly. In Proceedings of the 2019 CHI Conference on Human Factors in Computing Systems. 1-16.

[68] JaeHong Park, Prabhudev Konana, Bin Gu, Alok Kumar, and Rajagopal Raghunathan. 2010. Confirmation bias, overconfidence, and investment performance: Evidence from stock message boards. McCombs Research Paper Series No. IROM07-10 (2010).

[69] Richard E Petty and John T Cacioppo. 2012. Communication and persuasion Central and peripheral routes to attitude change. Springer Science \& Business Media.

[70] Alberto Peña and Alina Gómez-Mejía. 2019. Effect of the anchoring and adjustment heuristic and optimism bias in stock market forecasts. Revista Finanzas y Politica Economica 11, 2 (Jul 2019), 383-405. https://search.proquest.com/scholarly-journals/effect-anchoring-adjustmentheuristic-optimism/docview/2438995769/se-2?accountid=9902

[71] Jon Picoult. 2020. The Dark Side Of Customer Experience. https: //www.forbes.com/sites/jonpicoult/2020/11/18/the-dark-side-of-customerexperience/?sh=2086717b59e2

[72] Nathaniel Popper. 2020. Robinhood Has Lured Young Traders, Sometimes With Devastating Results. https://www.nytimes.com/2020/07/08/technology/ robinhood-risky-trading.html

[73] Emilee Rader, Kelley Cotter, and Janghee Cho. 2018. Explanations as Mechanisms for Supporting Algorithmic Transparency. Association for Computing Machinery, New York, NY, USA, 1-13. https://doi.org/10.1145/3173574.3173677

[74] Kate Rooney. 2020. Robinhood reports more monthly trades than rivals Charles Schwab, E-Trade combined. https://www.cnbc.com/2020/08/10/robinhoodreports-more-monthly-trades-than-rivals-charles-schwab-e-tradecombined.html

[75] Peter Rudegeair. 2021. Robinhood Faces Wrongful-Death Lawsuit Over Young Trader's Suicide. https://www.wsj.com/articles/robinhood-faces-wrongfuldeath-lawsuit-over-young-traders-suicide-11612813320?mod=lead_feature below_a_pos1

[76] Andrew Ross Sorkin, Jason Karaian, Michael J. De La Merced, Lauren Hirsch, and Ephrat Livni. 2021. Can Anything Stop GameStop? https://www.nytimes com/2021/01/27/business/dealbook/reddit-wallstreetbets-gamestop.html

[77] Keith E. Stanovich and Richard F. West. 2000. Individual differences in reasoning: Implications for the rationality debate? Behavioral and Brain Sciences 23, 5 (2000), 645-665. https://doi.org/10.1017/S0140525X00003435

[78] Meir Statman. 1987. How Many Stocks Make a Diversified Portfolio? The fournal of Financial and Quantitative Analysis 22, 3 (1987), 353-363. http://www.jstor. org/stable/2330969

[79] Barry M Staw and Jerry Ross. 1987. Behavior in escalation situations: Antecedents, prototypes, and solutions. Research in organizational behavior (1987).

[80] Christian Sturm, Alice Oh, Sebastian Linxen, Jose Abdelnour Nocera, Susan Dray, and Katharina Reinecke. 2015. How WEIRD is HCI? Extending HCI principles to other countries and cultures. In Proceedings of the 33rd Annual ACM Conference Extended Abstracts on Human Factors in Computing Systems. 2425-2428.

[81] Takumi Tanaka and Hideaki Kawabata. 2020. Interface predictability changes betting behavior in computerized gambling. Computers in Human Behavior 110
(2020), 106387. https://doi.org/10.1016/j.chb.2020.106387

[82] Amos Tversky and Daniel Kahneman. 1974. Judgment under uncertainty: Heuristics and biases. science 185, 4157 (1974), 1124-1131.

[83] Amos Tversky and Daniel Kahneman. 1981. The framing of decisions and the psychology of choice. science 211, 4481 (1981), 453-458.

[84] Amos Tversky and Daniel Kahneman. 1989. Rational choice and the framing of decisions. In Multiple criteria decision making and risk analysis using microcomputers. Springer, 81-126.

[85] Danding Wang, Qian Yang, Ashraf Abdul, and Brian Y. Lim. 2019. Designing Theory-Driven User-Centric Explainable AI. In Proceedings of the 2019 CHI Conference on Human Factors in Computing Systems (Glasgow, Scotland Uk) (CHI '19). Association for Computing Machinery, New York, NY, USA, 1-15. https://doi.org/10.1145/3290605.3300831

[86] Ivo Welch. 2020. The Wisdom of the Robinhood Crowd. Working Paper 27866. National Bureau of Economic Research. https://doi.org/10.3386/w27866

[87] Alex Wilhelm. 2020. As investing apps boom, Public doubles down on its social focus. https://techcrunch.com/2020/05/07/as-investing-apps-boom-publicdoubles-down-on-its-social-focus/

[88] Alex Wilhelm. 2020. Robinhood raises $\$ 200 \mathrm{M}$ more at $\$ 11.2 \mathrm{~B}$ valuation as its revenue scales. https://techcrunch.com/2020/08/17/robinhood-raises-200mmore-at-11-2b-valuation-as-its-revenue-scales/

[89] Alex Wilhelm. 2021. Trading app Public drops payment for order flow in favor of tips. https://techcrunch.com/2021/02/01/trading-app-public-drops-paymentfor-order-flow-in-favor-of-tips/

[90] Richard MS Wilson and Qing Zhang. 1997. Entrapment and escalating commitment in investment decision making: A review. The British Accounting Review 29, 3 (1997), 277-305.

[91] Ethan Wolff-Mann. 2021. 28\% of Americans bought GameStop or other viral stocks in January: Yahoo Finance-Harris Poll. https://finance.yahoo.com/news/ gamestop-amc-reddit-investing-213609595.html

[92] Kristin Wong. 2020. How Financial Apps Get You to Spend More and Question Less. https://www.wired.com/story/financial-apps-investing-dark-patterns/

[93] Michael Wursthorn and Euirim Choi. 2020. Does Robinhood Make It Too Easy to Trade? From Free Stocks to Confetti. https://www.wsj.com/articles/confettifree-stocks-does-robinhoods-design-make-trading-too-easy-11597915801

[94] Diyi Yang and Robert E. Kraut. 2017. Persuading Teammates to Give: Systematic versus Heuristic Cues for Soliciting Loans. Proc. ACM Hum.-Comput. Interact. 1, CSCW, Article 114 (Dec. 2017), 21 pages. https://doi.org/10.1145/3134749

[95] Viviana A Rotman Zelizer. 1997. The Social Meaning of Money. Princeton University Press.

[96] Fuzheng Zhang, Nicholas Jing Yuan, Kai Zheng, Defu Lian, Xing Xie, and Yong Rui. 2015. Mining consumer impulsivity from offline and online behavior. In Proceedings of the 2015 ACM International foint Conference on Pervasive and Ubiquitous Computing. 1281-1292.

[97] John Zimmerman, Jodi Forlizzi, Justin Finkenaur, Sarah Amick, Ji Young Ahn, Nanako Era, and Owen Tong. 2016. Teens, parents, and financial literacy. In Proceedings of the 2016 ACM Conference on Designing Interactive Systems. 312-322.

[98] Jason Zweig. 2015. Lessons of May Day 1975 Ring True Today: The Intelligent Investor. https://www.wsj.com/articles/lessons-of-may-day-1975-ring-truetoday-the-intelligent-investor-1430450405 